\title{
Editorial: Towards a Unifying Pan-Arctic Perspective of the Contemporary and Future Arctic Ocean
}

\author{
Paul Wassmann ${ }^{1 *}$, Dorte Krause-Jensen ${ }^{2,3}$, Bodil A. Bluhm ${ }^{1}$ and Markus Janout ${ }^{4}$ \\ ${ }^{1}$ Department of Arctic and Marine Biology, UiT - The Arctic University of Norway, Troms $\varnothing$, Norway, ${ }^{2}$ Department of \\ Bioscience, Aarhus University, Aarhus, Denmark, ${ }^{3}$ Arctic Research Centre, Aarhus University, Aarhus, Denmark, ${ }^{4}$ Alfred \\ Wegener Institute Helmholtz Centre for Polar and Marine Research, Bremerhaven, Germany
}

Keywords: physical forcing, freshening, ice, light, primary production, slopes, deep sea, future Arctic Ocean

Editorial on the Research Topic

Toward a Unifying Pan-Arctic Perspective of the Contemporary and Future Arctic Ocean

OPEN ACCESS

Edited by:

Yong Jiang,

Ocean University of China, China

Reviewed by:

Jinpeng Yang,

Sun Yat-Sen University, China

James W. McClelland,

University of Texas at Austin,

United States

*Correspondence:

Paul Wassmann

paul.wassmann@uit.no

Specialty section:

This article was submitted to Global Change and the Future Ocean, a section of the journal Frontiers in Marine Science

Received: 09 March 2021 Accepted: 10 May 2021

Published: 18 June 2021

Citation:

Wassmann P, Krause-Jensen D, Bluhm BA and Janout M (2021)

Editorial: Towards a Unifying

Pan-Arctic Perspective of the Contemporary and Future Arctic Ocean. Front. Mar. Sci. 8:678420. doi: 10.3389/fmars.2021.678420
An international symposium addressing pan-Arctic perspectives of the marine ecosystems of the Arctic Ocean took place in October 2017 and this editorial introduces the publications that derived from the conference. The symposium focused in particular upon physical forcing and biogeochemical cycling in surface waters of the Arctic Ocean, connectivity between surface and deep waters in the central basins and adjacent slopes and the ecology of the lesser-known shelf ecosystems. The symposium was the fourth in a sequence that has pan-Arctic integrations of Arctic Ocean ecosystems at its core. The series started in 2002 and its first volume was published under the title Structure and function of contemporary food webs on Arctic shelves (Wassmann, 2006). At the 2002-meeting, a suite of marine Arctic researchers from the main nations that work in the Arctic Ocean started applying the now-ubiquitous term pan-Arctic. The term underlined that the applied research goals and directions were more than a circumarctic perspective, but distinctly considered the entire expanse of the Arctic Ocean. Based upon this exercise, increased interest in the Arctic and some of the scientific endeavors of the 4th International Polar Year central projects and key oceanographers operating in the pan-Arctic region convened at the 2nd pan-Arctic integration symposium, entitled Arctic Marine Ecosystems in an Era of Rapid Climate Change in 2009 (Wassmann, 2011). After a decade of pan-Arctic research and building upon the foundation presented in Wassmann $(2006,2011)$ a 3rd conference was initiated in 2012, entitled Overarching perspectives of contemporary and future ecosystems in the Arctic Ocean (Wassmann, 2015).

This Research Topic brings together 13 publications from the 4th pan-arctic integration symposium held in 2017, entitled Toward a Unifying Pan-Arctic Perspective of the Contemporary and Future Arctic Ocean. We, the editors of the Research Topic, are delighted with the breadth, quality and diversity of the papers. We introduce the essence of the publications under three, summarizing headlines

- Physical connectivity, yet regionality

- What shapes pan-Arctic primary production

- The fate of production.

Toward the end we incorporate the knowledge presented in this volume into the overall progress and status of pan-Arctic marine ecosystem integration that has been achieved, so far, through the four pan-Arctic integration symposia. 


\section{PHYSICAL CONNECTIVITY, YET REGIONALITY}

Physico-chemical conditions shape the ecosystems within the Arctic Ocean and form the environmental envelopes that constrain key biotic processes. These environmental conditions create system connectivity across the Arctic Ocean, yet carry substantial regional signals, superimposed on the pan-Arctic scale, that create variability. System connectivity is exemplified by critical pan-Arctic aspects, including advective inputs that shape large regions and contiguous domains (Bluhm et al.; Polyakov et al.), the propagation of wave energy across the pan-Arctic shelves (Danielson et al.), the Arctic freshwater budget and the role of Arctic river runoff and meltwater on stratification (Brown et al.; Janout et al.), and related to that the vertical distribution, mixing and supply of nutrients (Randelhoff et al.). At the same time, several articles show that these very features are modulated by conditions specific to regions and contiguous domains that create functional diversity. This is for example shown in the variable strength of stratification (Brown et al.; Janout et al.; Polyakov et al.) as well as the divergent responses to climate change signals between the two basins (Polyakov et al.) and the upper and lower continental slope (Bluhm et al.).

As one example of pan-Arctic connectivity, Danielson et al. highlight continental shelf waves as a mechanism to transfer energy around the Arctic shelves. Their model- and observationsbased study finds that storm surges can trigger waves that have elevation maxima near the coasts and velocity maxima on the continental slopes. Slope regions are advective pathways discussed by Bluhm et al., and form a near-continuous band shaped by the Atlantic- and Pacific Water inflows. This alongslope connectivity significantly contrasts with the strong crossslope gradients in water masses and the dominance of physical processes. For instance, Randelhoff et al. provide a pan-Arctic view of vertical mixing and nutrient fluxes and find that these are greatest over the continental slopes, which explains the productive ecosystems in this narrow band (e.g., Ardyna et al.).

Stratification is a key parameter for ecosystem projections, as future ecosystem processes will include the balance between enhanced light levels allowed by longer open water periods, at the same time constraint by increased stratification due to enhanced ice melt and surface warming. Numerical ecosystem projections in fact suggest that the continental slope regions within the Atlantic water inflow region may be among the few regions where productivity increases due to reduced stratification and enhanced nutrient supply by the Atlantic water (Bluhm et al.). An increasing impact of the Atlantic- and Pacific Water inflows on the Arctic system (Atlantification and Pacification) is noticeable based on a nearly 4-decade-long observational archive presented by Polyakov et al. The most prominent changes include a salinification and weakened stratification along the Eurasian continental slope, while increasing Pacific water influx led to enhanced heat and freshwater levels in the Amerasian Basin and, in particular, in the Beaufort Gyre freshwater storage system. Freshwater is thus a key parameter in the Arctic Ocean, which directly controls the ecosystem through stratification and, hence, nutrient supply. Brown et al. conceptually highlight the integrative role of the freshwater on the Arctic ecosystem and biogeochemical conditions and underline the changing seasonality due to changes in the freeze-melt-cycle. Large rivers contribute significantly to the Arctic freshwater budget, and thus to its strong regionality. The focus of Janout et al. on the Lena-influenced Laptev Sea shelf underlines the river's importance for the regional and larger-scale shelf system. They further find that longer open water seasons will increase the variability of stratification and therefore reduce the predictability of the ecosystem.

\section{WHAT SHAPES PAN-ARCTIC PRIMARY PRODUCTION?}

Arctic marine primary production is contributed by planktonic algae and sea ice algae as well as by macroalgae, microalgae, and seagrasses on the seafloor. Although most studies focus on the pelagic compartment, benthic primary production may be considerable, e.g., constituting $35 \%$ of total primary production in a high-Arctic Greenland fjord, where sea ice algae contributed $<1 \%$ and phytoplankton contributed the rest (Rysgaard and Glud, 2007). A coarse upscaling suggests that benthic gross primary production amounts to $26 \%$ of annual phytoplankton net primary production across the Arctic Ocean (Attard et al., 2016). Light conditions, and hence indirectly sea ice and snow cover, are together with nutrient levels and water temperatures key determinants of primary production in the Arctic Ocean.

The overall reduction in extent and thickness of Arctic sea ice cover in combination with reduced snow cover on sea ice influences the amount of light entering the upper ocean and thereby affects primary production. Stroeve et al. combined data from satellites and models to map the pan-Arctic under-ice light scape for the past decade with monthly resolution. They stress the role of snow depth, especially at the time of the spring bloom, as well as ice thickness, which features prominently in the fall as key determinants of the light penetration supporting positive trends in under-ice PAR. The decrease in ice cover gave rise to the hypothesis that nitrate limitation of phytoplankton is becoming increasingly prominent. Randelhoff et al. showed that nitrate fluxes explained observed regional patterns and magnitudes of new primary production and that nutrient inventories are largely determined by the strength of stratification and by bathymetry. On this basis these authors suggested that vertical turbulent nitrate fluxes can be a reliable proxy for Arctic pelagic primary production.

Three articles of the Research Topic address temporal change and physical forcing on autotrophs (pelagic algae and sea ice algae) in the marine offshore Arctic (Ardyna et al.; Nöthig et al.; Hop et al.). Patterns in standing stocks of pelagic algae (chlorophyll $a$ ) and particulate organic carbon synthesized over 25 years varied across the Arctic with highest levels in the Fram Strait and Barents Sea and lowest levels in the most ice-covered regions of the central Arctic Ocean (Nöthig et al.). Over the study period, summertime chlorophyll stocks slightly increased 


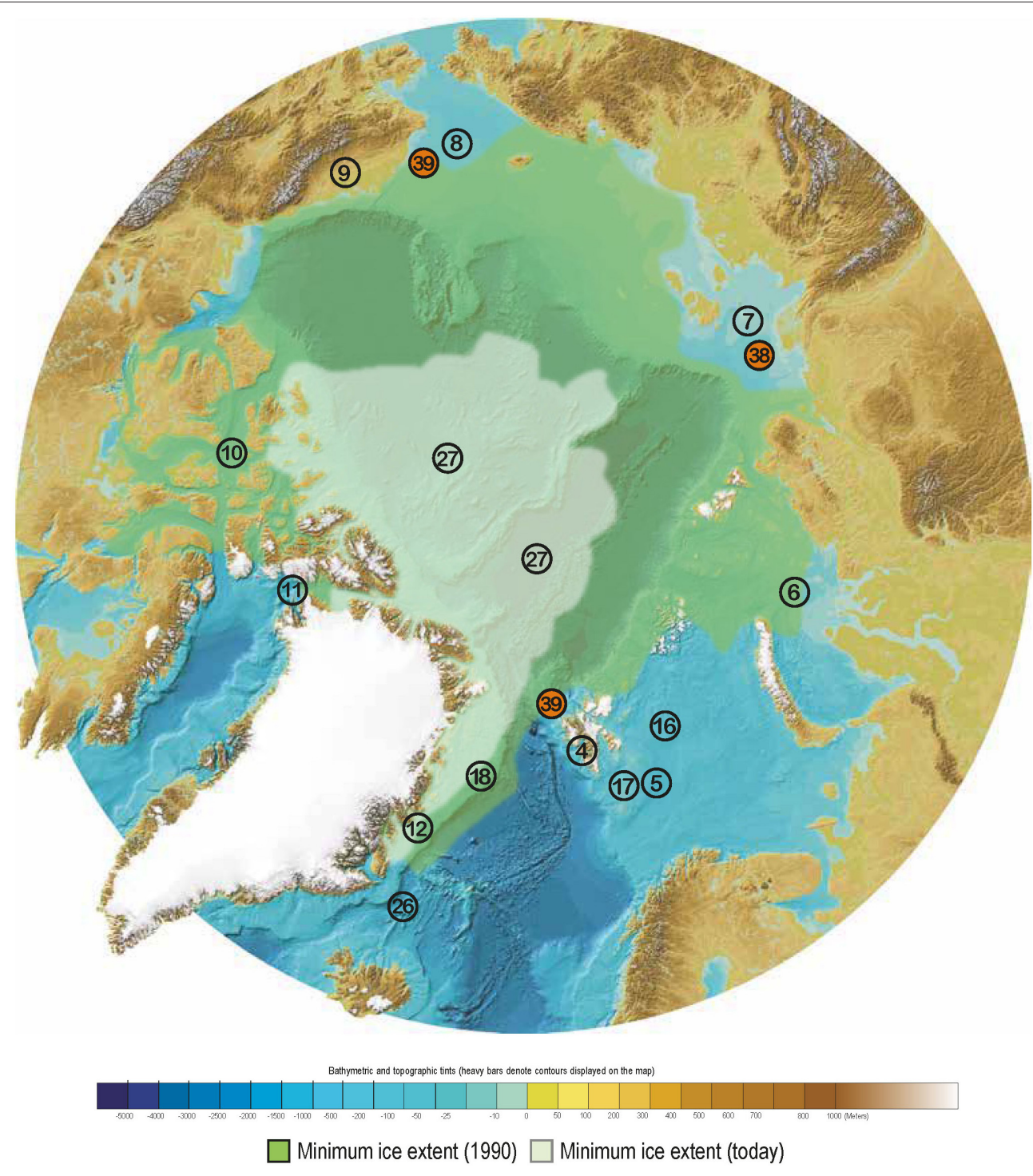

FIGURE 1 | Geographic distribution of pan-Arctic integration publications, i.e., pan-Arctic publications that address the ecological function of entire ecosystems. See Supplement 1 for a numbered overview of all pan-Arctic integration publications. The colored circles indicate the publications from the present volume.

in the Fram Strait but remained more or less constant in the central Arctic Ocean, while particulate organic carbon stocks eventually increased in the central Arctic Ocean. In addition to the open-water pelagic primary production, a so far underevaluated contribution to primary production is through underice blooms. Ardyna et al. highlights the changed phenology of the Arctic Ocean due to the increased under-ice light field. Based on a multidisciplinary approach, the authors provide a baseline of our current knowledge of under-ice blooms. Hop et al. studied seaice algae based on a data compilation of four decades across the central Arctic Ocean. They show that multiyear sea ice contains $\sim 40 \%$ more diatom species than first-year ice and that the recent decrease in multiyear sea ice has consequently led to decreased sea-ice protist diversity. Moreover, changing freeze-up scenarios as currently witnessed in the central Arctic also affected the biodiversity of sea-ice protists and might result in long-term changes in the community.

Benthic marine vegetation also responds to the major changes in the Arctic Ocean light and temperature regime. Temporal trends at 38 sites across the Arctic Ocean show that macroalgal and seagrass abundance, productivity and/or species richness have been increasing at most sites (Krause-Jensen et al.). Species distribution modeling support the finding of stimulated benthic primary production as the modeled current potential pan-Arctic macroalgal distribution area represents a major increase since 1940-1950 and associated polar migration rates averaging $18-23 \mathrm{~km}$ decade $^{-1} 1$ (Krause-Jensen et al.). 


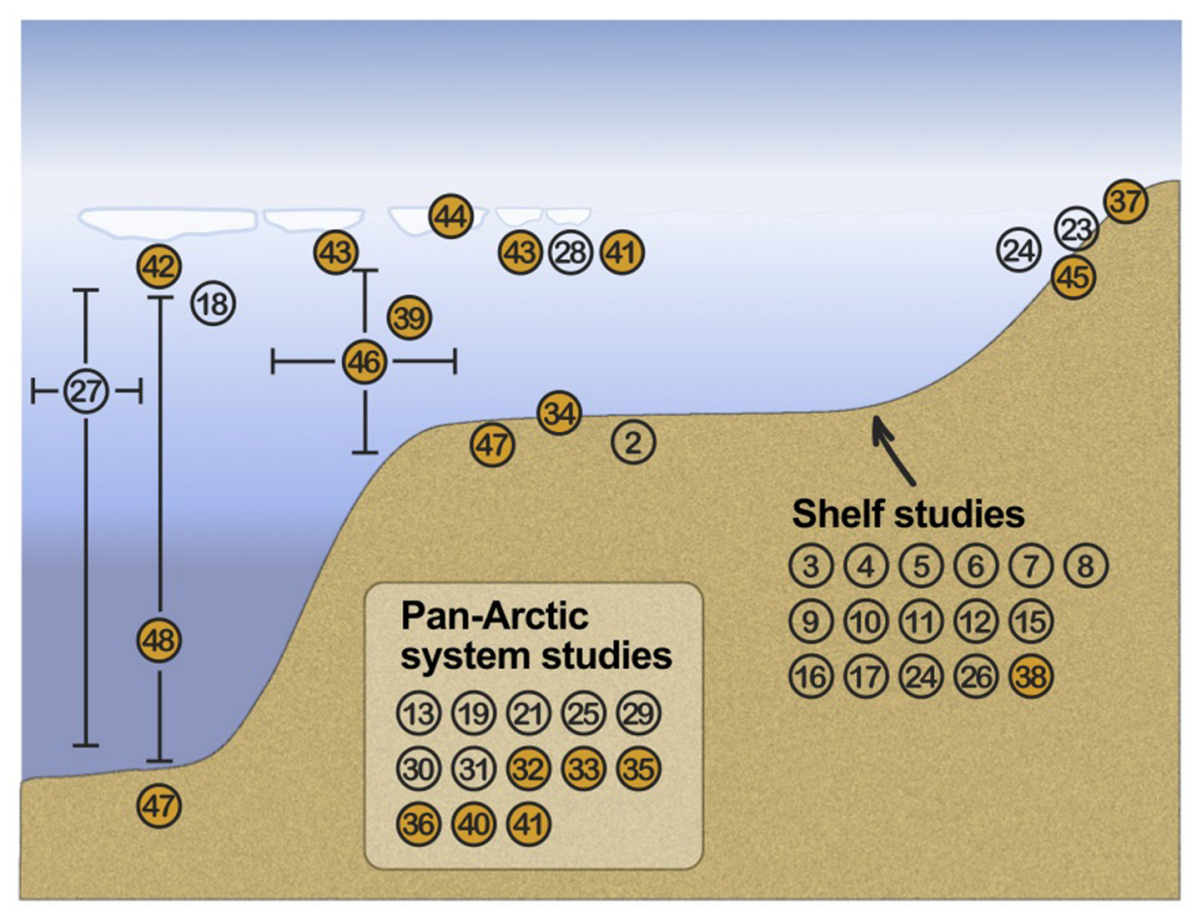

FIGURE 2 | An idealized cross section of the Arctic Ocean shelf and the distribution of publications that deal with particular ecosystem processes. The insert shows the publications dealing with processes investigated throughout the pan-Arctic Ocean expanse. The geographic shelf studies, presented in Figure 1 were excluded. The colored circles indicate the publications from the present volume.

\section{THE FATE OF PRODUCTION}

Regardless of the magnitude of primary production, standing stocks and composition of the underlying autotrophic community (e.g., Ardyna et al.; Krause-Jensen et al.; Nöthig et al.), only a small fraction of the organic material sinks out to the Arctic seafloor where it is partly remineralized by benthic biota. Kiesel et al. combined new field measurements of benthic diffusive and total oxygen uptake in the Barents Sea and Arctic Basins with comparable recent data from the Laptev and Beaufort Sea. Through this integration they document the dimension of difference in remineralization rates between shelf and basin areas, which are primarily related to the much lower availability of organic matter in the deeper areas. In contrast, they show that the highly variable bacterial abundances are only weakly related to remineralization levels. Wiedmann et al. expanded this perspective to a fully pan-Arctic level (here deeper than $1,000 \mathrm{~m}$ ). Through their compilation of published data on primary and secondary production, pelagic consumption, and vertical flux estimates, they identify a mismatch between carbon available to and estimates of carbon demand at the seafloor. They suggest this gap in the carbon budget may be due to missing event-based local carbon influxes such as those from fast-sinking algal aggregates, zooplankton carcasses as well as occasional large food falls. Carbon inputs are unequally distributed across the basins and margins. In their review of continental slopes,
Bluhm et al. highlight that biomass peaks at inflow slope regions in pelagic and benthic communities are related to strong inflows of particle-rich sub-Arctic waters and their subsequent transport along the boundary current at the upper slope. While along-slope and vertical exchange barriers maintain these gradients, cross-slope "leaks" facilitate shelf-basin exchange of water and carbon in both directions. All three author teams conclude that continued warming and declining sea ice is likely to enhance primary and secondary production with consequences for (possibly enhanced) vertical flux and remineralization at the seafloor yet acknowledging that inflow regions and upper ocean layers are the first to experience such changes.

\section{PROGRESS AND STATUS OF PAN-ARCTIC MARINE ECOSYSTEM INTEGRATION}

Pan-Arctic comprehension of marine ecosystems, subjected to the greatest climate change impacts of the planet, made further progress. How do the current publications regarding the physical forcing and biogeochemical cycling in surface waters, the connectivity between surface and deep basins and adjacent slopes and the ecology of the lesser-known shelf ecosystems fit into the overall picture of pan-Arctic integration? All 48 publications derived from the four panArctic integration symposia, presented and enumerated in 
Supplement 1 are shown in Figure 1 that illustrates the geographic distribution of these pan-Arctic publications that address the ecological function of entire ecosystems. The lack of integrative publications covering the eastern Barents Sea to the western Chukchi Sea and the central Arctic Ocean are obvious. More emphasis must not only be given to these regions in the future, but also to the highly variable Canadian Arctic Archipelago, Hudson Bay and Baffin Bay. Figure 2 illustrates an idealized and simplified cross section of the Arctic Ocean shelf and the distribution of publications that deal with particular ecosystem processes. Some integration effort has been dedicated to the seasonal ice zone and the shelfs the Arctic Ocean, while knowledge gathered from the slopes and basins is rather limited. Thirteen publications, shown as an insert in Figure 2 deal with particular processes that are investigated throughout the panArctic Ocean expanse. Over time, a development from specific geographic regions over particular ecosystem compartments toward processes throughout the pan-Arctic expanse can be noted. This development illustrates that pan-Arctic integration is well underway, despite remaining knowledge gaps. Based upon these publications and symposia a conceptual modeling toolkit in support of unifying the pan-Arctic perspective has been developed (Wassmann et al., 2020). To the major gaps belong off course the deep Arctic Ocean, and the entire expanse of the seasonal ice zone. The dynamics and processes near the land-sea interface of the inner shelves are also easily overlooked (changes in sea-ice cover, suspended sediment concentrations, light availability, and productivity) and are likely more complicated near-shore (see the Riverine Coastal Domain in Wassmann et al., 2020).

Future symposia should, for example, address the functioning of the seasonal ice zone and the dynamics over the slope regions. Not only is the Arctic subjected to the by far greatest climate change impact, but the seasonal ice zone is the ecosystem that is exposed to the greatest climate changes on earth. The changes in ice thickness, light availability, freshening and stratification result in fundamental changes that need our immediate attention.

\section{REFERENCES}

Attard, K. M., Hancke, K., Sejr, M. K., and Glud, R. N. (2016). Benthic primary production and mineralization in a High Arctic fjord: in situ assessments by aquatic eddy covariance. Mar. Ecol. Prog. Ser. 554, 35-50. doi: 10.3354/meps 11780

Rysgaard, S., and Glud, R. N. (Eds.). (2007). Carbon Cycling in Arctic Marine Ecosystems: Case Study Young Sound. Copenhagen: Meddelelser Om Grønland: Bioscience.

Wassmann, P. (Ed.). (2006). Structure and function of contemporary food webs on Arctic shelves: a pan-Arctic comparison. Progr. Oceanogr. 71, 123-477. doi: 10.1016/j.pocean.2006.09.008

Wassmann, P. (Ed.). (2011). Arctic marine ecosystems in an era of rapid climate change. Progr. Oceanogr. 90, 1-131. doi: 10.1016/j.pocean.2011.02.002

Wassmann, P. (Ed.). (2015). Overarching perspectives of contemporary and future ecosystems in the Arctic Ocean. Progr. Oceanogr. 139, 1-272. doi: 10.1016/j.pocean.2015.08.004

\section{AUTHOR CONTRIBUTIONS}

All authors contributed to designing and writing this editorial based on a draft prepared by PW.

\section{FUNDING}

The symposium, Research Topic and editorial is anchored in Arctic SIZE research group (http://site.uit.no/arcticsize/) and benefitted from support by UiT - The Arctic University of Norway. DK acknowledges support from the Independent Research Fund Denmark (CARMA, contract \# 8021-00222 B) and the EU Horizon 2020 (FACE-IT, contract \# 869154).

\section{ACKNOWLEDGMENTS}

We thank the participants of the 4th pan-Arctic integration symposium and all contributing authors and reviewers involved in this Research Topic. The hospitality, service, friendliness and the ambience of Hotel Kaštel in Motovun (among some participants better known under the term truffle mountain) contributed significantly to the highly efficient output of the meeting. Our thanks go also to the enthusiasm of the longterm volunteers in pan-Arctic marine ecosystem integration, in particular Eddy Carmack. Over the years his scope and ability to think along wide and long scales involved him in $20 \%$ of the publications in this series (Supplement 1). During the final stages of this volume, our good friend and colleague Vassily Spiridonov died from Covid-19. He was a brilliant scientist, very kind and a cheerful person, who we will miss in the further work toward pan-Arctic ecosystem integration. Rudi Caeyers prepared the figures.

\section{SUPPLEMENTARY MATERIAL}

The Supplementary Material for this article can be found online at: https://www.frontiersin.org/articles/10.3389/fmars. 2021.678420/full\#supplementary-material

Wassmann, P., Carmack, E. C., Bluhm, B. A., Duarte, C. M., Berge, J., Brown, K., et al. (2020). Towards a unifying pan-Arctic perspective: a conceptual modelling toolkit. Prog. Oceanogr. 189:102455. doi: $10.1016 /$ j.pocean.2020.102455

Conflict of Interest: The authors declare that the research was conducted in the absence of any commercial or financial relationships that could be construed as a potential conflict of interest.

Copyright (c) 2021 Wassmann, Krause-Jensen, Bluhm and Janout. This is an openaccess article distributed under the terms of the Creative Commons Attribution License (CC BY). The use, distribution or reproduction in other forums is permitted, provided the original author(s) and the copyright owner(s) are credited and that the original publication in this journal is cited, in accordance with accepted academic practice. No use, distribution or reproduction is permitted which does not comply with these terms. 